\title{
Balancing Work and Life When Self-Employed: The Role of Business Characteristics, Time Demands, and Gender Contexts
}

\author{
Emma Hagqvist ${ }^{1, *(\mathbb{D})}$, Susanna Toivanen ${ }^{2}$ and Claudia Bernhard-Oettel ${ }^{3}$ \\ 1 Department of Health Sciences, Mid Sweden University, 83182 Östersund, Sweden \\ 2 Department of Public Health Sciences, Stockholm University, 10691 Stockholm, Sweden; \\ susanna.toivanen@su.se \\ 3 Department of Psychology, Stockholm University, 10691 Stockholm, Sweden; claudia.bernhard.oettel@su.se \\ * Correspondence: emma.hagqvist@miun.se; Tel.: +46-010-142-8905
}

Received: 30 June 2018; Accepted: 10 August 2018; Published: 14 August 2018

\begin{abstract}
This study explores individual and contextual risk factors in relation to work interfering with private life (WIL) and private life interfering with work (LIW) among self-employed men and women across European countries. It also studies the relationship between interference (LIW and WIL) and well-being among self-employed men and women. Drawing on data from the fifth round of the European Working Conditions Survey, a sample of self-employed men and women with active businesses was extracted. After applying multilevel regressions, results show that although business characteristics are important, the most evident risk factor for WIL and LIW is time demands. Both time demands and business characteristics also seem to be important factors in relation to gender differences in level of interference. There is a relationship between well-being and both WIL and LIW, and time demands is again an important factor. Gender equality in the labor market did not relate to level of interference, nor did it affect the relationship between interference and well-being. However, in gender-separated analyses, LIW and LIW interacted with gender equality in the labor market in different ways for women's and men's well-being. In conclusion, gender relations are important in interference and how interference relates to well-being.
\end{abstract}

Keywords: contextual risk factors; gender; individual risk factors; life-work interference; self-employed; well-being; work-life interference

\section{Introduction}

Research has documented a more boundaryless life, in which the line between work and private life has become more blurry (Annink 2017; Hagqvist et al. 2017a; Fahlén 2014; Allvin et al. 2013; Mellner 2016; Mellner et al. 2014). When demands of paid work interfere with private life, or vice versa, it is referred to as work-life interference (Greenhaus and Beutell 1985). Interference is differentiated between paid work interfering with private life (WIL) and private life interfering with paid work (LIW). In the general working population, research shows that individuals experience higher levels of WIL than LIW (Byron 2005; Fahlén 2014). Meanwhile, it has been argued that both directions of interference are important for self-employed individuals (Beutell 2007), and few studies include both directions. Generally, self-employed individuals are defined as workers who work independently from an employer and who pursue gainful activity on their own account, with or without employees. In comparison to employees, self-employed individuals seem to experience more conflicting demands between work and private life than regular employees (Nordenmark et al. 2012; Bunk et al. 2012) and greater time strains (Hagqvist et al. 2015). However, there is a lack of consensus, as other research has found that employees report higher levels of conflict than self-employed individuals (Beutell 2007). 
Reasons for inconsistencies in comparing self-employed people to regular employees could be that those who are self-employed are often considered a homogenous group, neglecting variations due to, for example, business characteristics. Furthermore, many studies disregard contextual differences between countries. Exploring the concept of "doing gender" work is an arena in which gender relations are produced and reproduced (West and Zimmerman 1987). Femininities are expressed and strengthened by carrying out work tasks closely related to femininity, such as caring for home and family and having care-focused paid work (West and Zimmerman 1987; Connell 2002). In a similar manner, masculinities are emphasized through work by men, with values such as economic success and career being important. How genders are expressed and understood has nuances across contexts, which affect men's and women's conditions on both an individual and a contextual level (Kunovich and Kunovich 2008). This has a bearing on work specialization and interference across countries. Thus, there is a need to explore how business characteristics and time demands relate to interference across contexts.

A body of research shows that an imbalance between work and private life relates to low health and well-being among the general working population (Hagqvist et al. 2012; Hagqvist et al. 2017a; Lunau et al. 2014; Griep et al. 2016a; Griep et al. 2016b). The association varies across European countries. In Nordic countries, where labor markets are fairly gender equal, the imbalance between work and private life tends to relate to low well-being to a greater extent than in more gender-traditional countries where women have less access to labor markets (Hagqvist et al. 2017a; Drobnič et al. 2010). One reason for this may be the male norm that exists in the gender-equalizing discourse in Nordic countries. This may partly result in a high work burden for women and in norm-breaking behaviors among men when sharing housework. In the study of Hagqvist et al. (2017a), the general working population was studied, and no focus was placed on the self-employed.

Thus, by drawing on data of self-employed men and women across European countries, the aim of the present study is two-fold:

1. To identify whether any risk factors on an individual level (business characteristics and time demands) and a contextual level (gender equality on the labor market based on the economic session of Gender Global Gap Index 2015) relate to WIL and LIW, respectively, and to explore potential gender differences.

2. To study the relationship between interference (LIW and WIL) and well-being among self-employed men and women and to explore whether context (gender equality on the labor market) has different implications for how WIL and LIW relate to well-being in self-employed men and women.

\subsection{Interference of Work to Life and Life to Work}

Previous research is equivocal as to whether men or women experience higher levels of WIL. Some studies support the idea that women experience higher levels of interference (Leineweber et al. 2013; Falkenberg et al. 2017; Griep et al. 2016b), while others found that men experience higher levels (Fahlén 2014). On the other hand, Geurts and Demerouti (2003) suggested that there is no empirical evidence that gender differences exist. One reason for these different findings could be that neither contextual differences nor the socioeconomic position of the working men and women were taken into consideration in many of these studies. It has been suggested, for instance, that men and women doing higher-level professional nonmanual work experience more interference (Falkenberg et al. 2017; McGinnity and Calvert 2009), especially professional and highly educated women (Falkenberg et al. 2017; Griep et al. 2016a; Griep et al. 2016b). Gendered expectations in parental roles also seem to influence interference, as they increase mothers' WIL to a higher extent than fathers' (Fahlén 2014). A recent Swedish study suggested that women who chose self-employment to better balance work and private life also perceived less WIL (Johansson Sevä and Öun 2015).

Turning to LIW, Byron (2005) showed that men and women tend to report similar levels of LIW. A decade later, Fahlén (2014) presented evidence that women report higher levels of LIW than men 
do. Having greater responsibility for housework and family and child care and experiencing stress and time strain related to unpaid work seem to be risk factors for experiencing LIW (Byron 2005; Hagqvist et al. 2015). These are tasks women have more responsibility for and spend more time on than men, which can be one reason why women report higher levels of LIW. The fact that self-employment can be used as a way to balance work with family life, especially for women (Kirkwood and Tootell 2008; Kirkwood 2009; Annink et al. 2016), can result differences in men's and women's perception of LIW and WIL. For example, self-employed mothers in Canada seem to use self-employment to fit work around family demands and thus adjust work demands and work time to their children's needs (Hilbrecht and Lero 2014). Being able to fit work around family would imply that perhaps LIW is reduced among self-employed women. However, this may not be the case all around the globe. For example, in Scandinavia, strong job identification leads women to adapt to more masculine values in work and thus prioritize work before family and housework (Hagqvist et al. 2018).

In summary, previous research showed a complex and incomplete picture of WIL and LIW among self-employed men and women. There is evidence that gender differences and contextual differences matter in relation to interference and how men and women relate to work and family demands. What is missing is a comprehensive analysis of individual and contextual risk factors for developing LIW and WIL among the self-employed.

\subsection{Risk Factors for the Development of LIW and WIL in Self-Employment}

A bulk of studies have identified risk factors for experiencing WIL and LIW (fewer on LIW) in a general working population, neglecting the fact that circumstances might be different for self-employed individuals and that the group of self-employed is heterogeneous. In a general working population, risk factors for experiencing WIL include long working hours, working unsocial hours, high job demands, poor psychosocial work environment, partner's work hours, and parenthood (Bianchi and Milkie 2010; Crompton and Lyonette 2006; Fahlén 2014; Gallie and Russell 2009; Grönlund 2007; McGinnity and Calvert 2009). Also, for women, home demands, as well as economic strains, are associated with experiences of WIL (Fahlén 2014). Factors such as job flexibility, job control, and social support relate to lower risk of experiencing WIL (Grönlund 2007; Engman et al. 2017; Byron 2005). For women, long work hours, no job flexibility, and working unsocial hours seem to be more negative than for men (McGinnity and Calvert 2009; Fahlén 2014). Furthermore, women need very high levels of job flexibility to experience reduced levels of WIL (Grönlund 2007). Little is known about risk factors for LIW, but in contrast to WIL, LIW increases when there are high demands from the home domain rather than from paid work (Byron 2005; Fahlén 2014). In sum, different aspects from home and work seem to be differently associated with WIL and LIW in men and women. Also, here knowledge is inconclusive and somewhat limited, especially with regard to LIW. Therefore, home and work demands are explored as risk factors for WIL and LIW, respectively, for self-employed men and women in this study.

Self-employed individuals, when compared to regular employees, often report working longer and more irregular hours (Hagqvist et al. 2016; Nordenmark et al. 2012), often have higher work demands (Stephan and Roesler 2010), and many, especially men, experience being "always on," constantly working (Landstad et al. 2017; Hilbrecht and Lero 2014). Thus, it seems that self-employed individuals have high pressure at work and that work takes up a lot of their time, which are factors that increase levels of WIL. Meanwhile, despite high work demands, self-employed individuals often experience high levels of autonomy, flexibility, control, and freedom, which give them greater possibilities to juggle family demands and contribute to reducing the risk of experiencing WIL (Beutell 2007; Stephan and Roesler 2010; Byron 2005). Furthermore, time-use studies acknowledge gender differences among self-employed individuals compared to employees, as self-employed men and women seem to have a more gender stereotyped division between paid and unpaid work (Hagqvist et al. 2016). 
Among the self-employed, business setup and economic security might affect how well they have control over their time and what level of autonomy they actually have, which in turn can influence the risk of experiencing WIL. For instance, it has been shown that self-employed individuals who depend on clients and have little possibility to adapt their working hours and amount of work experience WIL more often than self-employed persons with low dependency on clients and high autonomy (Annink and den Dulk 2012; Kunda et al. 2002). Moreover, self-employed individuals with employees spend more time working (Craig et al. 2012), and long working hours increase the risk of interference. Also, Swedish self-employed women with employees seem to experience more WIL than men and self-employed women without employees (Johansson Sevä and Öun 2015).

Many individuals combine wage work with self-employment, especially in the transition from regular employment to self-employment (Wennberg et al. 2009). This phenomenon is often referred to as hybrid entrepreneurship, or combining entrepreneurship; here, the latter term is used. Not all individuals leave combining entrepreneurship over time; instead they continue to combine part-time self-employment with part- or full-time wage work (Nordström 2015). However, little is known about how combining entrepreneurship relates to an individual's life balance. It has been identified that the motivation for combining entrepreneurship is necessity for economic security or to be able to do work one is passionate about (e.g., crafting, painting, and/or music) (Nordström 2015; Thorgren et al. 2014). Whether it is out of passion or necessity, one can imagine that it demands long work hours, which could influence the risk of experiencing WIL.

To the best of our knowledge, few if any studies have so far identified risk factors for the onset of LIW among self-employed men and women. Some studies have explored demands between work and private life in general, not defining directions, and how self-employed men and women relate to these demands. These studies suggested that self-employed individuals experience strong job identification, which can blur the line between work and private life, causing feelings of interference or imbalance as such (Annink 2017; Hagqvist et al. 2018).

In this study, and corresponding to our first aim, business characteristics as risk factors for experiencing both WIL and LIW are explored with respect to combining entrepreneurship, being dependent on clients and having employees, and time demands, that is, time spent on paid work as well as on unpaid work.

\subsection{WIL, LIW, and Health}

Previous research has shown that there is a relationship between WIL and LIW interference and different health variables, including well-being, in a general working population (Lunau et al. 2014; Canivet et al. 2010; Leineweber et al. 2013; Hagqvist et al. 2012). In a study on self-employed individuals only, WIL was similarly related to reduced well-being (Nordenmark et al. 2012). For the general working population, it has been shown that the negative health consequences of WIL overshadow the positive effects of paid work (Hagqvist et al. 2012; Boye 2010). Thus, gender context seems to be an important factor for level of interference, but also for the relationship between interference and well-being.

Even if women tend to report WIL more often than men, experiencing WIL is directly correlated with poorer self-rated health in both women and men (Griep et al. 2016b; Hagqvist et al. 2017a; Lunau et al. 2014). WIL for men and women has been related to different health outcomes. For example, among men, high levels of WIL relate to increased alcohol intake, and among women, to elevated levels of burnout (Leineweber et al. 2013). Studies differentiating between time- and strain-based WIL show differences regarding health outcomes (Griep et al. 2016a; Griep et al. 2016b). Both types of WIL are associated with poor self-rated health (Griep et al. 2016b), yet strain-based WIL is associated particularly with migraine in women (Griep et al. 2016a). In men, migraine is associated with lack of time for personal care and leisure (Griep et al. 2016a). 


\subsection{Context and Level of Gender Equality in the Labor Market}

On a macro level, gender contextual differences might prompt how femininity and masculinity are expressed through work, and access to the labor market and division of paid and unpaid work. This can contribute to gender differences in experiences of WIL and LIW across countries (Hobson and Fahlén 2009; Hagqvist et al. 2017a; Drobnič et al. 2010). In order to better understand contextual differences contributing to gender differences in relation to work (gender contexts), the family-policy models constructed by Korpi (2000) and Thévenon (2011) can be used. In their studies, they organized countries based on social and family policy constructions representing more or less gender-equal contexts. Countries were clustered into different family-policy models. In more conservative contexts, often represented by countries from the south of Europe, few policies exist that support active labor market participation by both men and women, and child care is foremost relying on family responsibility (Korpi 2010; Thévenon 2011). Gender relations are often more traditional; what is considered feminine and masculine is based on more traditional values, and thus work tasks are less equally divided. In dual-earner policy models that are typical for countries in the north of Europe, family-friendly policies are more progressive, with public-funded kindergartens and paid parental leave for either parent (Ibid.). Thus, more women take a greater part in the labor market and spend more time on paid work (Hagqvist et al. 2017b). A third group refers to market-oriented contexts (the Anglo-Saxon countries), and these largely lack publicly funded child care; care is instead largely provided by the market and relatives (Korpi 2010; Thévenon 2011). Thus, different contexts give men and women different possibilities to take part in the labor market and have a career (Korpi et al. 2013), which is visualized in data showing that full-time-equivalent employment for women is higher in dual-earner countries than in conservative or market-oriented countries (The European Institute for Gender Equality (EIGE) 2013).

Some studies show that in a general working population, men and especially women in dual-earner contexts report higher levels of WIL than men and women in countries with more conservative values (Cousins and Tang 2004; Van der Lippe et al. 2006). Others show that WIL is just as high in dual-earner as in other contexts (Grönlund and Öun 2010). Still other studies show that among full-time working women, the level of WIL is highest in more conservative contexts (Boye 2011; Lunau et al. 2014). Thus, gender context and women's ability to take part in the labor market seem to be important to the level of interference.

On a macro level, studies of cross-country differences in the relationship between interference and well-being are still scarce, and results are somewhat divergent, especially with regard to self-employment. In recent articles, the relationship between WIL and well-being was studied across a general working population in different gender contexts (Hagqvist et al. 2017a; Drobnič et al. 2010). Findings showed that the level of WIL is lower in dual-earner countries; however, in these countries, the negative relationship between WIL and well-being is stronger than in countries representing conservative/traditional and market family policy models. There is a lack of studies focusing on contextual differences in the relationship between LIW and well-being and between interference and well-being for the self-employed. In sum, there are differences in the level of interference between self-employed individuals and regular employees and there are gender differences in how men and women relate to, and use, self-employment in different contexts. Therefore, and corresponding to our second aim, we investigate the relationship between interference and well-being across countries for self-employed men and women.

\section{Method}

This paper is based on data from the European Working Conditions Survey (EWCS) 2015. EWCS is a cross-sectional cross-country study covering 35 OECD countries. Included in this study are people who were reported to be actively self-employed, resulting in a sample of 6977 , of which $36.7 \%$ were women and $63.3 \%$ were men. 
This sample of self-employed individuals makes up $16.8 \%$ of the total population (40,987 individuals) who answered the EWCS. This corresponds well with the proportion of self-employed workers $(16.1 \%)$ in the European Union in 2015 (OECD 2018). The proportion of women among self-employed people is lower than among employees ( $50 \%$ women among employees). The mean age of those reporting to be self-employed compared to employees was somewhat older ( 45 vs. 40 years). Self-employed individuals in EWCS 2015 reported significantly higher levels of both WIL and LIW than regular employees. Levels of well-being were similar across the two groups. Furthermore, self-employed men worked the longest hours, and self-employed women worked the shortest, compared to women and men in regular employment. On the other hand, self-employed women spent on average $146 \mathrm{~min}$ of their time on housework each day, which is more than what regularly employed women spent, and considerably more than what men in general spent on housework.

\subsection{Measurement}

WIL and LIW were combined from several questions to produce indices ranging from low levels to high levels of interference. WIL was constructed using three questions (Cronbach's alpha $=0.694$ ), resulting in an index ranging from 0 to 12. Questions (Q45A-C in EWCS) probed how often in the last 12 months the respondents (1) worried about paid work when not at work, (2) felt too tired after paid work to enjoy the things they normally did, and (3) found that their job prevented them from spending time with their family. The LIW index was constructed using 2 questions (Q45D-E in EWCS), asking respondents if they (1) found it difficult to concentrate on the job because of family responsibility and (2) found that family responsibility prevented them from giving the time they should to their job. In both cases, answers ranged from "never" to "always" on a 5-point Likert scale. LIW index ranged from 0 to 8 (Cronbach's alpha $=0.747$ ). Well-being was measured using a composite index of 5 questions (the World Health Organization Well-Being Index; Q87A-E) asking whether, over the last 2 weeks, the respondents felt (1) cheerful and in good spirits, (2) calm and relaxed, (3) active and vigorous, (4) fresh and rested when waking up, or (5) that daily life has been filled with things that interest them (Cronbach's alpha $=0.881$ ). Questions were answered on a 6-point scale ranging from "never" to "all the time", providing an index ranging from 0 (low well-being) to 25 (high well-being).

Individual-level measurements were included as a means to detect differences among self-employed men and women. These consisted of business characteristics and time demands. Business characteristics were measured using 3 dichotomized variables: (1) whether the self-employed respondents had employees (having employees was set as the redundant), (2) whether respondents were combining entrepreneurs (non-combiners were set as the redundant), and (3) whether respondents had more than one client (one client was set as the redundant). Time demands were measured as (1) minutes spent on unpaid housework per day and (2) hours spent on paid work per week.

Furthermore, we included 4 individual control variables based on respondents' answers on the questionnaire: (1) living with children in the household (no children in the household was set as the redundant), (2) partner's time in paid work, (3) age, and (4) perspectives on their household economy. Regarding household economy, included as an indicator of socioeconomic position, respondents were asked whether they believed their household made ends meet, on a 6-point scale ranging from "very easy" to "with great difficulty." The 6-point scale was merged to split variables: good economy (set as the redundant), fair economy, and bad economy.

One macro variable was used as a proxy for gender context measuring gender equality in the labor market. The contextual measurement was based on the economic participation and opportunity section of the 2015 global gender gap index (GGGI) (World Economic Forum 2015), which measures gender equality in working life across countries. The GGGI consists of 3 areas: (1) the participation gap (i.e., the ratio of female to male labor force participation), (2) the remuneration gap (i.e., wage equity between men and women for similar work), and (3) the advancement gap (i.e., the ratio of women to men among legislators, senior officials and managers, and technical and professional workers). 
A value of 1 on the GGGI score signifies perfect equity, whereas 0 indicates the highest level of inequity. The GGGI scores are presented in Appendix A.

\subsection{Analyses}

IBM SPSS Statistics was used for all analyses. The analyses had 3 steps. First, descriptive analyses were conducted, and by using independent T-test (for continuous variables) and chi-square test (for categorical variables), we studied differences across variables for self-employed men and women.

In the second step, and corresponding to the first aim of this study, we applied a multilevel model to identify individual- and context-level risk factors for reporting WIL and LIW. In a stepwise structure, first a null model was computed, then gender was added, and then the control variables. Following, risk factors were explored in 3 different models, first the 3 business characteristics variables, then the 2 time demands variables, and finally GGGI. In the last model, all individual variables, as well as GGGI, were added.

Next, and corresponding to the second aim of this study, the relationships between well-being and both WIL and LIW were analyzed. Also, here, a stepwise structure was used. First, interference was added, then gender, followed by control variables. Risk factors were tested in the same structure as above, first business characteristics, then time demands, and last GGGI. Thereafter, GGGI was added. Next, a random slope was used to explore the relationships between well-being and WIL and LIW across contexts. Finally, an interaction between GGGI and interference was tested.

For all multilevel models, beta values, significance level, interclass correlation (ICC), and model fit measure log likelihood (LL2) are presented. All analyses were weighted for sample and design differences across countries using weights provided in the EWCS dataset.

\section{Results}

Starting with results from the descriptive analyses studying distributions and differences between women and men, Table 1 shows that self-employed women experienced significantly higher levels of interference in both directions than self-employed men. Self-employed men, on the other hand, reported higher levels of well-being than women did. Men's partners worked fewer hours than women's partners. Women reported worse household economy than men did. Looking at the individual business characteristics risk factors, Table 1 shows that women more often had no employees (i.e., were solo entrepreneurs) and were more often combining entrepreneurs. Men more often had more than one client. Moreover, results of time demand variables show that self-employed women spent less time on paid work and more time on housework compared to self-employed men.

Table 1. Distribution and gender differences across variables. WIL, work interfering with private life; LIW, private life interfering with work.

\begin{tabular}{lccc}
\hline & Women & Men & Significance Level \\
\hline WIL & 5.20 & 5.00 & 0.008 \\
\hline LIW & 2.06 & 1.77 & 0.000 \\
\hline Well-being & 16.73 & 17.42 & 0.000 \\
\hline Business characteristics: & & & \\
No employees (\%) & 76.1 & 69.3 & 0.000 \\
Combining entrepreneurs (\%) & 9.3 & 6.9 & 0.000 \\
$>$ 1 client (\%) & 76.1 & 80.0 & 0.000 \\
\hline Time demands: & & & \\
Paid work (hours/week) & 38.1 & 45.3 & 0.000 \\
Unpaid work (minutes/day) & 148.1 & 104.2 & 0.000 \\
\hline Control variables: & & & 0.000 \\
Children living in the household (\%) & 60.9 & 51.4 & 0.000 \\
Partner's work hours & 43.1 & 36.7 & 0.000 \\
Age (years) & 44.8 & 46.3 & 0.000 \\
Household economy & & & \\
$\quad$ Good (\%) & 28.3 & 34.4 & \\
$\quad$ Fair (\%) & 27.2 & 28.1 & \\
$\quad$ Poor (\%) & 44.5 & 37.5 & \\
\hline
\end{tabular}




\subsection{Individual and Contextual Risk Factors}

Tables 2 and 3 depict how potential individual- and contextual-level risk factors are associated with WIL and LIW among self-employed men and women. Starting with WIL (Table 2), initially Model 2 confirmed the result from Table 1, that self-employed women reported higher levels of WIL compared to men. However, when including individual control variables (Model 3; children living in the household, partner's working time, age, and household economy), results show that self-employed women reported lower levels of WIL than men did, and children living in the household was the variable changing this relationship. The relationship between having children in the household and WIL was significant and quite high. Thus, having children in the household seemed to be an important factor in relation to WIL and a more prominent risk factor for self-employed women than for self-employed men.

Table 2. Exploring individual and contextual risk factors for WIL using a multilevel model. GGGI, global gender gap index; ICC, interclass correlation; LL2, log likelihood.

\begin{tabular}{|c|c|c|c|c|c|c|c|}
\hline & Model 1 & Model 2 & Model 3 & Model 4 & Model 5 & Model 6 & Model 7 \\
\hline Intercept & $4.897^{*}$ & $4.845^{*}$ & $4.609 *$ & $4.521 *$ & $2.206 *$ & $4.705 *$ & 2.387 \\
\hline Women & & $0.141^{* *}$ & $-0.367^{*}$ & $-0.232 * *$ & $0.520 * *$ & -0.368 * & $0.561 * *$ \\
\hline Children living in the household & & & $0.624 *$ & $0.595 *$ & $0.331 * *$ & $0.624 *$ & 0.276 \\
\hline Partner's work time & & & $0.016^{*}$ & $0.016^{*}$ & 0.002 & $0.016^{*}$ & 0.004 \\
\hline Age & & & $-0.020 *$ & $-0.019 *$ & -0.017 & $-0.020 *$ & $-0.019^{* *}$ \\
\hline Fair economy & & & $0.481 *$ & $0.522 *$ & 0.276 & $0.480 *$ & 0.238 \\
\hline Poor economy & & & $0.910 *$ & $1.083 *$ & $0.858 *$ & 0.908 * & $0.976^{*}$ \\
\hline No employees & & & & $-0.555^{*}$ & & & $-0.410^{* *}$ \\
\hline Combining entrepreneur & & & & $0.349^{x}$ & & & $0.718^{* *}$ \\
\hline$>1$ client & & & & $0.297 * *$ & & & 0.325 \\
\hline Work hours & & & & & $0.050 *$ & & $0.050 *$ \\
\hline Housework & & & & & $0.003^{* *}$ & & $0.003^{* *}$ \\
\hline GGGI & & & & & & -0.140 & -0.182 \\
\hline Residual & $8.018 *$ & $8.015^{*}$ & $6.799 *$ & $6.687^{*}$ & $6.091 *$ & $6.799 *$ & $6.090 *$ \\
\hline Country intercept & 0.530 * & 0.528 * & 0.389 * & 0.392 * & $0.296^{* *}$ & 0.403 * & $0.276^{* *}$ \\
\hline $\operatorname{ICC}(\%)$ & 6.2 & 6.2 & 5.4 & 5.5 & 4.6 & 5.6 & 4.3 \\
\hline LL2 & $34,023.84$ & $34,023.38$ & $14,328.00$ & $13,826.24$ & 6300.61 & $14,325.02$ & 5992.57 \\
\hline
\end{tabular}

In Models 4 and 5, individual level risk factors in relation to WIL were explored. Starting with model fit, in comparison to Model 3, models with individual-level risk factors significantly improved the fit, indicating that both business characteristic and time demand variables better explained the individual variation in WIL. Among the business characteristics, results show that those who had employees and those who had more than one client reported higher levels of WIL. Combining entrepreneurship was borderline significant to WIL $(p=0.057)$. Moving to time demand variables, more time spent on both paid and unpaid work was significantly related to increased levels of WIL. Also, the intercept considerably decreased, emphasizing the importance of time demands as a risk factor for experiencing WIL among self-employed individuals.

Importantly, while business characteristics seemed to reduce gender differences in reported level of WIL, time demands changed the relationship, and women instead of men reported significantly higher levels of WIL. This demonstrates that time demands seem to influence self-employed men and women differently. To explore this further, separate models were run for men and women, and results are presented below.

Turning to contextual-level factor and impact, the initial Model 1 showed that country of residence explained $6.2 \%$ of the variation in WIL on an individual level. Country of residence, accordingly, had little but some influence on self-employed individuals' risk of experiencing WIL. Impact from country was reduced when individual control factors were included (Model 3). However, time demands (Model 5) had yet more impact on the reduction of ICC, indicating that part of the country variation in WIL was explained by country differences in time demands. In Model 6, the presumed contextual 
level risk factor (GGGI) was added, and results show that level of gender equality in the labor market did not relate to individuals' reported WIL.

Last, in Model 7, business characteristics, time demands, and GGGI were jointly included. Results show that there is some covariance. Compared to previous models, Model 7 shows that combining entrepreneurship became a significant factor and the beta value increased. Having more than one client became insignificant. These results imply that these two business characteristics are sensitive to time demands. It is worth noticing that after adding GGGI in Model 7, only marginal changes occurred on all beta values across individual-level factors; however, the intercept became insignificant (data available upon request). An insignificant intercept demonstrates that covariance exists between individual and contextual risk factors extinguishing WIL among self-employed individuals. Furthermore, gender differences again changed character compared to previous models, and women reported significantly higher levels of WIL.

Exploring LIW, Table 3 shows individual- and contextual-level risk factors in relation to LIW. Different from WIL, Table 3 shows that women reported higher levels of interference, and this difference did not change when adding individual control variables.

Table 3. Exploring individual and contextual risk factors for LIW using a multilevel model.

\begin{tabular}{|c|c|c|c|c|c|c|c|}
\hline & Model 1 & Model 2 & Model 3 & Model 4 & Model 5 & Model 6 & Model 7 \\
\hline Intercept & $1.751 *$ & $1.651 *$ & $1.668 *$ & 1.691 * & $1.623 *$ & $2.068 * *$ & $1.989 * *$ \\
\hline Women & & 0.273 * & 0.218 * & $0.216^{*}$ & 0.236 & $0.216^{*}$ & 0.247 \\
\hline Children living in the household & & & $0.465 *$ & 0.473 * & $0.433 *$ & 0.464 * & $0.413 *$ \\
\hline Partner's work time & & & 0.001 & 0.001 & -0.003 & 0.001 & -0.004 \\
\hline Age & & & $-0.011 *$ & $-0.011 *$ & $-0.018^{*}$ & $-0.011 *$ & $-0.018^{*}$ \\
\hline Fair economy & & & $0.269 *$ & $0.268 *$ & $0.302 * *$ & $0.267^{*}$ & $0.307 * *$ \\
\hline Poor economy & & & $0.438 *$ & $0.432 *$ & $0.582 *$ & $0.433 *$ & $0.593 *$ \\
\hline No employees & & & & 0.039 & & & -0.012 \\
\hline Combining entrepreneur & & & & $0.311^{* *}$ & & & $0.481^{* *}$ \\
\hline$>1$ client & & & & -0.100 & & & -0.144 \\
\hline Work hours & & & & & $0.010 *$ & & $0.009^{* *}$ \\
\hline Housework & & & & & 0.000 & & 0.000 \\
\hline GGGI & & & & & & -0.584 & -0.261 \\
\hline Residual & $3.072 *$ & $3.055^{*}$ & $2.690 *$ & $2.694^{*}$ & $2.872 *$ & $2.690 *$ & $2.936^{*}$ \\
\hline Country intercept & $0.115^{*}$ & 0.113 * & $0.074 * *$ & $0.079 * *$ & $0.083^{* *}$ & $0.075^{* *}$ & $0.090 * *$ \\
\hline $\operatorname{ICC}(\%)$ & 3.6 & 3.6 & 2.7 & 2.9 & 2.8 & 2.7 & 3.0 \\
\hline LL2 & $27,694.65$ & $27,660.50$ & $11,657.42$ & $11,273.80$ & 5282.10 & $11,655.45$ & 5044.98 \\
\hline
\end{tabular}

For individual-level risk factors, Table 3 shows that model fit marginally improved when business characteristics were added and substantially when time demands were added, demonstrating that time demands better explain individual differences in LIW than business characteristics. Models 4 shows that among the business characteristics, only combining entrepreneurship was related to increased levels of LIW. Among time demands, more time spent on paid work significantly increased the risk of LIW, while time spent on housework had no significant relationship with LIW. However, though time spent on housework was insignificant, adding the variable to the model made gender differences insignificant, implying that time spent on housework has different importance for self-employed men and women.

Country variation in individuals' experiences of LIW was rather small and decreased when individual control variables were included in Model 3. ICC thereafter remained stable, indicating that country differences in LIW were explained by differences across individual control variables. In Model 6, GGGI was added, and the results show that there was no significant relationship between level of gender equality in the labor market and level of LIW.

When all variables were included in Model 7, results show that compared to previous models, only marginal changes occurred among individual-level risk factors. Again, gender differences became insignificant.

In summary, business characteristics were related to increased levels of WIL but not LIW. Having employees or more than one client related to increased risk of experiencing WIL. Time demands, 
on the other hand, related to both WIL and LIW and were more important with regard to interference than business characteristics. Importantly, time demands seemed to influence men and women differently. All in all, there is a need to further explore the importance of gender differences.

\subsection{Gender, WIL, and LIW}

As identified above, there seemed to be gender differences in risk factors for experiencing WIL and LIW. Thus, gender was further explored by studying men and women separately (Table 4). This was not part of the initial analytical plan, but was carried out as a result of the above findings.

Table 4. Separate multilevel analysis for men and women exploring WIL and LIW.

\begin{tabular}{|c|c|c|c|c|}
\hline & \multicolumn{2}{|c|}{ WIL } & \multicolumn{2}{|c|}{ LIW } \\
\hline & Women & Men & Women & Men \\
\hline Intercept & $3.559 * *$ & 0.074 & $3.144^{* *}$ & -2.624 \\
\hline Children living in the household & $0.375^{x}$ & -0.200 & $0.395^{* *}$ & 0.524 * \\
\hline Partner's work time & 0.005 & 0.002 & -0.006 & 0.007 \\
\hline Age & -0.010 & $-0.048 *$ & $-0.016^{* *}$ & -0.025 * \\
\hline Fair economy & 0.045 & $0.783^{* *}$ & 0.271 & 0.359 \\
\hline Poor economy & 0.757 * & $1.707 *$ & $0.461 * *$ & $0.889 * *$ \\
\hline No employees & -0.299 & -0.405 & 0.082 & -0.101 \\
\hline Combining entrepreneur & $1.154 *$ & -0.126 & 0.462 & 0.359 \\
\hline$>1$ client & 0.364 & 0.166 & -0.221 & 0.318 \\
\hline Work hours & $0.045 *$ & $0.051 *$ & $0.009 *$ & 0.013 * \\
\hline Housework & $0.004^{* *}$ & 0.001 & 0.001 & 0.000 \\
\hline GGGI & -1.693 & 5.602 & -0.162 & 5.410 \\
\hline Residual & $6.078 *$ & $5.672 *$ & $3.135 *$ & $1.849 *$ \\
\hline Country intercept & $0.349^{* *}$ & 0.318 & 0.106 & 0.723 \\
\hline $\operatorname{ICC}(\%)$ & 5.4 & NA & NA & NA \\
\hline LL2 & 4606.08 & 1387.49 & 3953.33 & 1078.30 \\
\hline
\end{tabular}

Beginning with WIL, separate analyses for men and women show that household economy, age, and time spent on paid work were risk factors for experiencing WIL among self-employed men. However, for men the intercept was insignificant, and when GGGI was added to all other variables, intercept and country intercept became insignificant. For women, on the other hand, the intercept was higher than in Table 2 (see Model 7). Similar to men, poor household economy and time spent on paid work were significantly related to increased levels of WIL. However, different from men, unpaid work and combining entrepreneurship were important to self-employed women's risk of experiencing WIL. Furthermore, having children in the household was borderline significant. For women, beta value for combining entrepreneurship was rather high, indicating that women who combined regular employment with running their own business struggled with equal demands from work and private life. Furthermore, while no country variance existed for men, for women, country of residence accounted for $5.4 \%$ of the variation in WIL. The interpretation is that context is not important for men, while for women contextual differences are evident.

Regarding LIW, Table 4 shows that in line with WIL, the intercept for men was insignificant, while for women it increased. This suggests that excluding the effect of control variables, time demands, and business characteristics, men did not experience LIW. Nevertheless, having children in the household, hours spent on paid work, and age were evident risk factors for LIW among both men and women. For men and women, context did not influence an individual's risk of experiencing LIW.

In sum, for self-employed women, different from self-employed men, both WIL and LIW were substantial. Long work hours and having children in the household cause struggles and demands, influencing directions of interference for both women and men. In addition, for increased reports of WIL among women, time spent on housework and combining entrepreneurship were risk factors. Among self-employed men, neither individual nor country intercept was significant. 


\subsection{Well-Being, WIL, and LIW}

The second aim of this study was to explore the relationship between well-being and LIW with respect to WIL, and to test whether there were differences in the relationship depending on context and gender equality in the labor market. Starting with WIL, among self-employed men and women, a negative relationship between WIL and well-being was found (Table 5, Model 1), which remained stable when individual control variables and gender were included (Model 2; individual control variables not shown). Of the individual level risk factors, none of the business characteristics (Model 3) were significantly related to well-being. For time demands, only time spent on paid work was positively and significantly related to well-being. Furthermore, model fit improved significantly when time demands were included. Again, after adding time demands, gender difference changed remarkably, with gender differences in well-being eradicated.

Table 5. Relationship between WIL and well-being.

\begin{tabular}{|c|c|c|c|c|c|c|c|c|c|}
\hline & Model 1 & Model $2^{a}$ & Model $3^{a}$ & Model $4^{a}$ & Model $5^{a}$ & Model $6^{b}$ & Model $7^{b}$ & Model $8^{b}$ & Model $9^{b}$ \\
\hline Intercept & $20.179 *$ & $23.580 *$ & $23.465 *$ & $23.206^{*}$ & $21.882 *$ & $23.192 *$ & $20.161 *$ & $17.712 *$ & $17.878 *$ \\
\hline WIL & -0.547 * & $-0.511 *$ & $-0.523 *$ & $-0.576^{*}$ & $-0.511 *$ & -0.570 * & -0.570 * & -0.003 & 0.153 \\
\hline Women & & $-0.489 * *$ & $-0.417^{* *}$ & 0.089 & -0.484 * & 0.081 & 0.118 & 0.105 & -0.106 \\
\hline No employees & & & -0.125 & & & & & & \\
\hline Combining entrepreneur & & & -0.121 & & & & & & \\
\hline$>1$ client & & & 0.202 & & & & & & \\
\hline Work hours & & & & $0.034 *$ & & & & & \\
\hline Housework & & & & -0.001 & & & & & \\
\hline GGGI & & & & & 2.466 & & 4.345 & 7.946 & 8.582 \\
\hline GGGI ${ }^{x}$ WIL & & & & & & & & -0.832 & -0.962 \\
\hline Residual & $21.967 *$ & $17.547 *$ & $17.566 *$ & $17.831 *$ & $17.548^{*}$ & $17.775 *$ & 17.754 * & $17.751 *$ & $17.966 *$ \\
\hline Country intercept & $0.994 *$ & $0.806 *$ & $0.822 *$ & $0.847 *$ & $0.808^{*}$ & 0.787 ** & $0.746 *$ & $0.749^{* *}$ & $0.896 * *$ \\
\hline ICC $(\%)$ & 4.3 & 4.4 & 4.5 & 4.5 & 4.7 & 4.2 & 4.0 & 4.0 & 4.8 \\
\hline Variance of random slope & & & & & & 0.005 & 0.007 & 0.007 & \\
\hline LL2 & $40,600.40$ & $17,046.04$ & $16,501.42$ & 7682.42 & $17,041.40$ & 7682.02 & 7675.98 & 7673.45 & 7834.70 \\
\hline
\end{tabular}

Country variance of self-employed individuals' well-being was low: $5.1 \%$ (results shown on request). When WIL was added, ICC was reduced to $4.3 \%$ (Model 2). ICC then remained stable around $4.3 \%$ across models. This indicates that WIL explains part of the contextual variance in individuals' well-being. GGGI did not have a significant relationship with well-being, and variance of random slope was insignificant (Model 6). Finally, level of gender equality in the labor market did not moderate the relationship between WIL and well-being: when the interaction term was included in Model 7, the relationship between WIL and well-being became insignificant, and in Model 8, WIL was still insignificant.

Table 6 shows the results of the analysis of the relationship between LIW and well-being. Model 1 shows that higher levels of LIW were related to lower levels of well-being. This relationship became marginally weaker when individual control variables were included (Model 2). It is worth noticing that the relationship between gender and well-being was insignificant and remained so throughout all models. This illustrates that when the effect of LIW is removed, there are no gender differences in well-being.

Table 6. Relationship between LIW and well-being.

\begin{tabular}{|c|c|c|c|c|c|c|c|c|c|}
\hline & Model 1 & Model $2^{a}$ & Model $3^{a}$ & Model $4^{a}$ & Model $5^{a}$ & Model $6^{b}$ & Model $7^{b}$ & Model $8^{b}$ & Model $9^{b}$ \\
\hline Intercept & $18.795 *$ & $22.062 *$ & $21.907 *$ & 22.858 & 20.574 * & $22.840 *$ & $20.013 *$ & $19.981 *$ & $19.804 *$ \\
\hline LIW & $-0.752 *$ & $-0.637^{*}$ & $-0.645^{*}$ & $-0.729 *$ & $-0.637^{*}$ & -0.717 * & $-0.721 *$ & -0.434 & -0.412 \\
\hline Women & & -0.081 & -0.087 & 0.057 & -0.077 & 0.049 & 0.088 & 0.082 & -0.007 \\
\hline No employees & & & 0.223 & & & & & & \\
\hline Combining entrepreneur & & & -0.174 & & & & & & \\
\hline$>1$ client & & & 0.086 & & & & & & \\
\hline Work hours & & & & 0.015 & & & & & \\
\hline Housework & & & & -0.003 & & & & & \\
\hline GGGI & & & & & 2.162 & & 4.063 & 4.696 & 4.895 \\
\hline
\end{tabular}


Table 6. Cont.

\begin{tabular}{|c|c|c|c|c|c|c|c|c|c|}
\hline & Model 1 & Model $2^{a}$ & Model $3^{a}$ & Model $4^{a}$ & Model $5^{a}$ & Model $6^{\text {b }}$ & Model $7^{\text {b }}$ & Model $8^{b}$ & Model $9^{b}$ \\
\hline GGGI $^{x}$ IW & & & & & & & & -0.429 & -0.450 \\
\hline Residual & $22.649 *$ & $18.094 *$ & $18.112 *$ & $18.097^{*}$ & $18.095 *$ & $17.957 *$ & $17.944 *$ & $17.944 *$ & $17.975 *$ \\
\hline Country intercept & $1.087 *$ & $0.931 *$ & $0.991 *$ & $0.861 *$ & $0.944 *$ & $0.726^{* *}$ & $0.720 * *$ & $0.716^{* *}$ & $0.913 * *$ \\
\hline ICC $(\%)$ & 4.6 & 4.9 & 5.2 & 4.5 & 4.9 & 3.9 & 3.9 & 3.8 & 4.8 \\
\hline Variance of random slope & & & & & & 0.048 & 0.050 & 0.055 & \\
\hline LL2 & $41,263.18$ & $17,305.92$ & $16,718.67$ & 7689.84 & $17,301.44$ & 7688.09 & 7682.25 & 7680.01 & 7822.81 \\
\hline
\end{tabular}

${ }^{a}$ Controlled for by children, partner's work hours, age, and household economy. ${ }^{b}$ Controlled for by children, partner, household economy, age, work hours, and housework. * $p$ equal to or less than 0.001 . ** $p$ between 0.05 and 0.002 .

None of the individual-level variables were significantly related to well-being. Furthermore, business characteristics did not seem to influence the relationship between LIW and well-being. Time demands marginally influenced the relationship between LIW and well-being by increasing the strength between the two. This pinpoints the importance of time spent on paid and unpaid work in relation to LIW.

As with WIL, contextual impact was small. ICC was fairly low when LIW was included and changed only marginally across models, and reduced somewhat when the random slope was added in Model 6. The random slope was insignificant. Similarly, GGGI had an insignificant relationship with well-being, and GGGI had no moderating impact on the relationship between LIW and well-being: when the interaction term was introduced in Model 8, the relationship between LIW and well-being became insignificant and remained insignificant in Model 12.

In summary, results indicate that context and level of gender equality in the labor market were insignificant for the relationship between well-being and WIL and LIW among self-employed individuals in Europe. Business characteristics had no relationship with well-being, nor did they influence the relationship between well-being and WIL and LIW. The one thing that seemed important for well-being in relation to WIL and LIW was time demands, especially time spent on housework. Results indicate that gender and time demands seem to play important roles in the relationship between well-being and both directions of interference, and they were therefore investigated further.

\subsection{Gender and Gender Context for the Relationship between WIL, LIW, and Well-Being}

When analyzing men and women separately, interesting patterns occur. In the relationship between WIL and well-being, both GGGI and the interaction term were significant for self-employed women but not for men (see Table 7). This shows that for women, level of gender equality was somewhat important, and for self-employed women in more gender-equal countries, the relationship between WIL and well-being was stronger. For men, though, neither the interaction term nor GGGI was significant. ICC showed $19.7 \%$ variance, which signals that men in different countries differed in how they reported WB, after LIW and GGGI were accounted for. Such country differences were not found in men WB after LIW and GGGI were assessed.

Different from WIL, with regard to LIW, the interaction term was significant for men but not for women. Self-employed men in more gender-equal countries had a stronger negative relationship between LIW and well-being compared to self-employed men in more gender-traditional contexts.

Taken together, we found differences depending on the gender of self-employed individuals and country of residence. First, results show that women reported significantly lower well-being than men when controlling for WIL, but when controlling for LIW, no gender difference in well-being was seen (Tables 5 and 6). Second, in gender-separate analyses (Table 7), living in countries with more gender-equal labor markets made a difference in the relationship between well-being and LIW for self-employed men and the relationship between WIL and well-being for women. 
Table 7. Relationship between WIL and well-being and LIW and well-being, for men and women separately, with well-being as the outcome variable; controlled for by children, partner, household economy, age, work hours, and housework.

\begin{tabular}{|c|c|c|c|c|}
\hline & \multicolumn{2}{|c|}{ WIL } & \multicolumn{2}{|c|}{ LIW } \\
\hline & Women & Men & Women & Men \\
\hline Intercept & $17.231 *$ & $30.474 *$ & $20.153 *$ & 27.849 * \\
\hline Interference & 0.601 & -2.244 & 0.345 & $-6.280 * *$ \\
\hline GGGI & $11.313^{* *}$ & -13.473 & 6.533 & -11.321 \\
\hline $\begin{array}{l}\text { GGGI }^{x} \\
\text { interference }\end{array}$ & $-0.612 * *$ & 2.376 & -1.544 & $7.581 * *$ \\
\hline Residual & $17.817^{*}$ & $15.916 *$ & 17.641 * & $16.248^{*}$ \\
\hline Country intercept & $0.763^{* *}$ & $3.915 * *$ & $0.691^{* *}$ & 3.569 \\
\hline $\operatorname{ICC}(\%)$ & 4.1 & 19.7 & 3.8 & NA \\
\hline LL2 & 6006.38 & 1805.14 & 6004.71 & 1785.03 \\
\hline
\end{tabular}

\section{Discussion}

The overall aim of this paper was two-fold: first, we aimed to identify individual and contextual risk factors in relation to WIL and LIW among self-employed men and women across European countries, and second, we studied the relationship between interference (LIW and WIL) and well-being among self-employed men and women.

First, addressing the individual risk factors, comprising business characteristics specified for self-employed individuals and time demands, results show that while business characteristics are related to increased levels of WIL, no significant relationship was found for LIW. Specifically, as indicated in previous studies (Annink and den Dulk 2012; Kunda et al. 2002), having more than one client was associated with an increased risk of experiencing WIL. Having employees has been shown to increase time spent on work (Craig et al. 2012), and in this study we also find that having employees is a risk factor for experiencing WIL. In addition, though weak, combining self-employment with regular employment also seems to be a risk factor for WIL, especially for women, who, more often than men, combined these two employment roles. However, business characteristics had no significant relationship with well-being, nor did they influence the relationships between well-being and WIL and LIW. On the contrary, time demands seemed to be important for both level of interference and the relationships between well-being and WIL and LIW.

Reasons for being a combining entrepreneur can vary and depend on necessity or passion. One can imagine that depending on these reasons, the risk of experiencing interference can differ. Furthermore, an important factor in relation to interference is time spent on wage work and one's own business (Nordström 2015). In this study, there was no way to differentiate between reasons for time spent on work and one's own business. However, it did become evident that when the effects of other business characteristics and time demands are removed, the relationship between combining entrepreneurship and WIL becomes significant, with a high beta value, and for LIW, the beta value increased. This demonstrates that combining entrepreneurship is important and should be further investigated, as well as when and why it occurs more often for self-employed women than men. All the included business characteristics, being dependent on clients, managing employees, and combining entrepreneurship, are factors that could cause extra demands, work time, and feelings of being "always on" for self-employed individuals that, in turn, can increase the risk of experiencing WIL and LIW. For instance, Craig et al. (2012) confirmed this argument, since their results showed that self-employed individuals with employees spent more time working. Our conclusion is that when studying interference among self-employed men and women, it is important not to treat the group as homogeneous but to acknowledge the differences within the group, especially with regard to factors that take a lot of time and have to do with business demands. In this study, a few business characteristics are explored, but others exist. For example, ownership, the existence of a management 
board, location of the business (at home or outside the home), and time since business start-up could represent risk factors for experiencing interference. Lastly, because of the relevance of time demands that this study identified, different business characteristics should be investigated in relation to time use and job demands.

Both WIL and LIW showed some country differences, especially WIL; however, individual differences seem to be more important. Unlike in previous studies (Hagqvist et al. 2017a; Drobnič et al. 2010), gender equality in the labor market was not related to men's and women's experiences of interference. A possible explanation for this somewhat surprising finding may be that women's access to the labor market might have a greater impact on regular employees.

In line with other studies (Nordenmark et al. 2012), we found that WIL was negatively related to well-being for self-employed men and women in Europe. Adding to previous research, we can also demonstrate that there is a negative relationship between LIW and well-being, strengthening the conclusion of Beutell (2007), who stated that both directions of interference should be considered when studying self-employed individuals. Business characteristics were important for level of interference, but had no further direct association with well-being when interferences were accounted for. In contrast, time demands were directly linked to well-being, even when interferences were considered. However, other business factors may have to be considered in future studies, and there is a need to explore how distribution of time spent in work and non-work life affects interferences and well-being in self-employed individuals in different life and business circumstances.

Unlike the result of Hagqvist et al. (2017a), we found no support for contextual differences in the relationship between interference and well-being, and the level of gender equality in the labor market did not seem to play a role either. This may be related to the fact that self-employment and regular employment differ; policies enabling individuals to balance work and family might not be as beneficial for self-employed individuals; therefore, perhaps the effect of gender context may be reduced.

Focusing on gender provides some additional insights into the above picture. In the results, it becomes evident that self-employed men and women have different working and living conditions, which in turn cause differences in the experience of interferences and in how well-being and interference are related to each other. When first looking at gender differences, women report higher levels of both WIL and LIW. However, when we adjust for the effect of children living in the household, partner work hours, household economy, and age, men report higher levels of WIL, with children having the greatest impact. For women, partner work hours and having children at home specifically increased WIL, while household economy and age induced feelings of WIL among men. While gender differences remained stable when business characteristics were added, time demands played a significant role in gender differences. In general, these results indicate that WIL and LIW are influenced by how self-employed men and women divide their time, and in doing so, how they produce and reproduce gender roles in work and life (West and Zimmerman 1987). Factors such as long work hours and poor household economy emerged as risk factors for both WIL and LIW among men. As breadwinners, men might feel a stronger burden in relation to low household economy, which could inflict greater pressure to work long hours (Connell 2008). Housework and child care are more often women's tasks (Connell 2002), and in line with how femininity is constructed, having children in the household, long work hours, and time spent on work were related to increased levels of interference among women. As shown by McGinnity and Calvert (2009), our study supports the idea that time spent on paid work affects self-employed women's level of WIL to a greater extent than men's. Also, when the effect of time spent on housework is accounted for, no gender difference in WIL exists. Similar to WIL, LIW shows that removing time spent on housework eradicates gender differences. Rather surprisingly, long work hours relate to increased levels of LIW for both men and women, while time spent on housework merely relates to WIL. This could perhaps be an expression of women's guilt over wanting to be home when at work, and perhaps men's guilt over not helping enough at home (Hagqvist et al. 2018). This study also shows that women report significantly lower levels of well-being than men when controlling for WIL, but when controlling for LIW, no gender 
difference in well-being exists. This reveals how important balance between work and non-work is when we seek to understand gender differences in well-being, and there is a need to further study such aspects, particularly in the self-employed. In conclusion, for both WIL and LIW, time spent on both paid and unpaid work plays an important role in gender differences in experiences of interference. Reflecting back on the effect of business characteristics on level of interference, it becomes evident that more studies are needed to explore how such characteristics can affect men and women differently, and furthermore if business characteristics might be gendered. This also emphasizes the importance of considering the gender process at work when studying self-employed men and women.

Although results indicate that the context and level of gender equality in the labor market are insignificant to the level of interference or the relationship between well-being and WIL and LIW among the self-employed, in a gender aspect they do. From previous studies, it is evident that in more gender-equal contexts, work is more evenly divided between couples (Fuwa 2004), and women have better opportunities to take part in the labor market (Hagqvist et al. 2017b; Korpi et al. 2013). In separate analyses, our results show that country influences women's level of interference, but not men's. Secondly, as shown by separate analyses, living in countries with more gender-equal labor markets has an influence on women's well-being in relation to WIL and on men's well-being in relation to LIW. In countries with more gender-equal labor markets, well-being was more negatively affected by WIL for women and LIW for men. In a recent study by Hagqvist et al. (2018), in interviews with Scandinavian small-business managers, it became evident that self-employed women adapted to masculine behavior by doing management. When women were doing management, they strongly identified as managers and with their jobs, causing them not to reflect on a high workload and long work hours as something abnormal and conflicting. Rather, it was the norm and part of the deal of being a manager (Hagqvist et al. 2018). This approach to management differs rather explicitly from an approach in which women, and especially mothers, use self-employment as a way to balance work and family (Annink et al. 2016; Kirkwood 2009; Kirkwood and Tootell 2008), and it may be worthwhile studying whether such an approach is more often chosen by self-employed women in more gender-traditional contexts. Furthermore, in Scandinavia compared to more gender-traditional countries, men spend more time on housework and child care, but still not the same amount as women (Hagqvist et al. 2017b). This could be a reason why LIW relates to lower well-being in more gender-equal contexts for men.

\section{Strengths and Limitations}

Like research in general, there are both strengths and limitations to this study. A strength is the explicit, large-scale dataset covering working individuals in Europe. The dataset allows for multilevel structuring, exploring both individual and contextual factors. In this study, the multilevel structure was taken advantage of by adding contextual-level measurements. The main and foremost limitation is the cross-sectional structure of the data, and the impossibility of further exploring, for example, other business characteristics or reasons for starting a business. Also, more detailed information on how exactly time was divided for different work activities or private life and home duties was not available, but would have been of interest to better understand the meaning of time demands.

\section{Conclusions}

This study contributes to previous studies by providing extended knowledge of specific individual and contextual factors regarding the risk of experiencing interference among self-employed men and women in Europe and how interference relates to well-being. Most importantly, it adds to previous knowledge by demonstrating the importance of gender and gender context to how self-employed individuals in Europe experience interference and how interference relates to well-being.

Specifically, the conclusions are that business characteristics are important foremost for the level of paid work interfering with private life, emphasizing the importance of differentiating the self-employed group in future studies. However, though this study highlights the importance of acknowledging the 
heterogeneity within the self-employed group, time demands seems to be the most evident risk factor for level of interference. It is important to recognize how different aspects of self-employment, such as having employees, number of clients, and combining entrepreneurship, can affect time demands, which in turn affect interference. Other business characteristics, such as the existence of administrative support, business setup (e.g., the existence of a board), branch, and business location (whether it is run from home) can also affect time and should be further investigated.

A main conclusion of this study is that gender is an important risk factor in experiencing paid work interfering with private life, private life interfering with paid work, and how interference relates to well-being, on both an individual and a contextual level. Gender differences are foremost illustrated by how time demands and having children at home relate to interference, and furthermore, how interference relates to well-being. In the concept of doing gender, these results suggest that masculinity and femininity seem to be more explicit among self-employed individuals. Perhaps this is a result of a selection process in the motivating factors, both for becoming self-employed and for the choice of branch and business setup. These factors need more attention in future research.

For the relationship between interference and well-being, women's opportunity to take part in the labor market seems to be important. For self-employed men and women in more gender-equal countries, where women work longer hours and men feel guilty for not participating more in housework, there is a daily struggle of demands that in turn affects well-being. Saying that, it is not equality per se that is the cause of the problem but how work is still highly gendered, and how time demands are distributed. Policies and government ideologies support a male norm and do not acknowledge that gender equality must be discussed in a broader context of work in general, and in the context of self-employment in particular, To this end, more research studies are needed in order to reduce the knowledge gap regarding gendered processes in relation to self-employment.

Author Contributions: E.H. designed the study, analyzed the data and wrote the first draft of the paper; C.B.-O. contributed with valuable comments, discussions and in refining the manuscript; S.T. has developed the project and was the main applicant receiving the grant from the Swedish Work Environment Authority, she has also contributed with comments on the work in progress.

Funding: This research was funded by the Swedish Work Environment Authority (Grant No. 2015/033753-31) and the Swedish Research council for Work and Health (2017-01063) for financing this study.

Conflicts of Interest: The authors declare no conflict of interest.

\section{Acronyms}

$\begin{array}{ll}\text { GGGI } & \text { gender gap index } \\ \text { EWCS } & \text { European Working Conditions Survey } \\ \text { ICC } & \text { inter class correlations } \\ \text { LL2 } & \text { Log likelihood } \\ \text { LIW } & \text { Private life interfering with paid work } \\ \text { OECD } & \text { Organization for Economic Co-operation and Development } \\ \text { WIL } & \text { Paid work interfering with private life } \\ \text { WHO } & \text { Workld Health Organisation }\end{array}$

\section{Appendix A}

Table A1. Included countries and respective GGGI.

\begin{tabular}{cc}
\hline Country & GGGI \\
\hline Albania & 0.668 \\
Austria & 0.650 \\
Belgium & 0.731 \\
Bulgaria & 0.716 \\
Croatia & 0.672 \\
\hline
\end{tabular}


Table A1. Cont.

\begin{tabular}{|c|c|}
\hline Country & GGGI \\
\hline Cyprus & 0.665 \\
\hline Czech Republic & 0.647 \\
\hline Denmark & 0.735 \\
\hline Estonia & 0.703 \\
\hline Finland & 0.794 \\
\hline France & 0.676 \\
\hline FYROM & 0.658 \\
\hline Germany & 0.691 \\
\hline Greece & 0.649 \\
\hline Hungary & 0.672 \\
\hline Ireland & 0.709 \\
\hline Italy & 0.574 \\
\hline Latvia & 0.785 \\
\hline Lithuania & 0.757 \\
\hline Luxembourg & 0.750 \\
\hline Malta & 0.595 \\
\hline Montenegro & 0.647 \\
\hline The Netherlands & 0.659 \\
\hline Norway & 0.818 \\
\hline Poland & 0.690 \\
\hline Portugal & 0.713 \\
\hline Romania & 0.699 \\
\hline Serbia & 0.670 \\
\hline Slovakia & 0.648 \\
\hline Slovenia & 0.784 \\
\hline Spain & 0.668 \\
\hline Sweden & 0.802 \\
\hline Switzerland & 0.745 \\
\hline Turkey & 0.464 \\
\hline UK & 0.700 \\
\hline
\end{tabular}

\section{References}

Allvin, Michael, Christin Mellner, Fredrik Movitz, and Gunnar Aronsson. 2013. The diffusion of flexibility: Estimating the incidence of low-regulated working conditions. Nordic Journal of Working Life Studies 3: 99-116. [CrossRef]

Annink, Anne, Laura Den Dulk, and José Ernesto Amorós. 2016. Different strokes for different folks? The impact of heterogeneity in work characteristics and country contexts on work-life balance among the self-employed. International Journal of Entrepreneurial Behavior \& Research 22: 880-902.

Annink, Anne. 2017. From social support to capabilities for the work-life balance of independent professionals. Journal of Management $\mathcal{E}$ Organization 23: 258-76.

Annink, Anne, and Laura den Dulk. 2012. Autonomy: The panacea for self-employed women's work-life balance? Community, Work \& Family 15: 383-402.

Beutell, Nicholas J. 2007. Self-employment, work-family conflict and work-family synergy: Antecedents and consequences. Journal of Small Business E Entrepreneurship 20: 325-34.

Bianchi, Suzanne M., and Melissa A. Milkie. 2010. Work and family research in the first decade of the 21st century. Journal of Marriage and Family 72: 705-25. [CrossRef]

Boye, Katarina. 2010. Time spent working. Is there a link between time spent on paid work and housework and the gender difference in psycological disterss? European Societies 12: 419-42. [CrossRef]

Boye, Katarina. 2011. Work and well-being in a comparative perspective-The role of family policy. European Sociological Review 27: 16-30. [CrossRef]

Bunk, Jennifer A., Alicia G. Dugan, Amy L. D'Agostino, and Janet L. Barnes-Farrell. 2012. Understanding work-to-family conflict among self-employed workers: Utilising a cognitive appraisal framework. Journal of Entrepreneurship 21: 223-51. [CrossRef] 
Byron, Kristin. 2005. A meta-analytic review of work-family conflict and its antecedents. Journal of Vocational Behavior 67: 169-98. [CrossRef]

Canivet, Catarina, Per-Olof Östergren, Sara I. Lindeberg, BongKyoo Choi, Robert Karasek, Mahnaz Moghaddassi, and Sven-Olof Isacsson. 2010. Conflict between the work and family domains and exhaustion among vocationally active men and women. Social Science and Medicine 70: 1237-45. [CrossRef] [PubMed]

Connell, Robert W. 2002. Gender. Cambridge: Polity.

Connell, Robert W. 2008. Maskuliniteter. Göteborg: Daidalos.

Cousins, Christine R., and Ning Tang. 2004. Working time and work and family conflict in The Netherlands, Sweden and the UK. Work, Employment E Society 18: 531-49.

Craig, Lyn, Abigail Powell, and Natasha Cortis. 2012. Self-employment, work-family time and the gender division of labor. Work, Employment E Society 26: 716-34.

Crompton, Rosemary, and Clare Lyonette. 2006. Work-life balance' in Europe. Acta Sociologica 49: 379-93. [CrossRef]

Drobnič, Sonja, Barbara Beham, and Patrick Präg. 2010. Good job, good life? Working conditions and quality of life in Europe. Social Indicators Research 99: 205-25. [CrossRef]

Engman, Frida, Anna Nordin, and Emma Hagqvist. 2017. Obalans mellan arbetet och privatlivet bland offentliganställda: Betydelsen av kontroll och socialt stöd på arbetsplatsen. Socialmedicinsk Tidskrift 94: 610-22.

Fahlén, Susanne. 2014. Does gender matter? Policies, norms and the gender gap in work-to-home and home-to-work conflict across Europe. Community, Work \& Family 17: 371-91.

Falkenberg, Helena, Petra Lindfors, Tarani Chandola, and Jenny Head. 2017. Do gender and socioeconomic status matter when combining work and family: Could control at work and at home help? Results from the Whitehall II study. Economic and Industrial Democracy. [CrossRef]

Fuwa, Makiko. 2004. Macro-level gender inequality and the division of household labor in 22 countries. American Sociological Review 69: 751-67. [CrossRef]

Gallie, Duncan, and Helen Russell. 2009. Work-family conflict and working conditions in Western Europe. Social Indicators Research 93: 445-67. [CrossRef]

Geurts, Sabine AE, and Evangelia Demerouti. 2003. Work/non-work interface: A review of theories and findings. In The Handbook of Work and Health Psychology. New York: John Wiley \& Sons, vol. 2, pp. 279-312.

Greenhaus, Jeffrey H., and Nicholas J. Beutell. 1985. Sources of conflict between work and family roles. Academy of Management Review 10: 76-88. [CrossRef]

Griep, Rosane Härter, Susanna Toivanen, Itamar S. Santos, Lucia Rotenberg, Leidjaira Lopes Juvanhol, Alessandra C. Goulart, Estela M. Aquino, and Isabela Benseñor. 2016a. Work-family conflict, lack of time for personal care and leisure, and job strain in migraine: Results of the Brazilian Longitudinal Study of adult Health (ELSA-Brasil). American Journal of Industrial Medicine 59: 987-1000. [CrossRef] [PubMed]

Griep, Rosane Härter, Susanna Toivanen, Cornelia Van Diepen, Joanna MN Guimarães, Lidyane V. Camelo, Leidjaira Lopes Juvanhol, Estela M. Aquino, and Dóra Chor. 2016b. Work-family conflict and self-rated health: The role of gender and educational level. Baseline data from the Brazilian Longitudinal Study of Adult Health (ELSA-Brasil). International Journal of Behavioral Medicine 23: 372-82. [CrossRef] [PubMed]

Grönlund, Anne. 2007. More control, less conflict? Job demand-control, gender and work-family conflict. Gender, Work \& Organization 14: 476-97.

Grönlund, Anne, and Ida Öun. 2010. Rethinking work-family conflict: Dual-earner policies, role conflict and role expansion in Western Europe. Journal of European Social Policy 20: 179-95. [CrossRef]

Hagqvist, Emma, Katja Gillander Gådin, and Mikael Nordenmark. 2012. Division of labor, perceived labor-related stress and well-being among European couples. Open Journal of Preventive Medicine 2: 452-60. [CrossRef]

Hagqvist, Emma, Susanna Toivanen, and Stig Vinberg. 2015. Time strain among employed and self-employed women and men in Sweden. Society, Health $\mathcal{E}$ Vulnerability 6: 29183.

Hagqvist, Emma, Susanna Toivanen, and Stig Vinberg. 2016. The gender time gap: Time use among self-employed women and men compared to paid employees in Sweden. Time E Society. [CrossRef]

Hagqvist, Emma, Katja Gillander Gådin, and Mikael Nordenmark. 2017a. Work-Family Conflict and Well-Being across Europe: The Role of Gender Context. Social Indicators Research 132: 785-97. [CrossRef]

Hagqvist, Emma, Mikael Nordenmark, Glòria Pérez, Sara Trujillo Alemán, and Katja Gillander Gådin. 2017b. Parental leave policies and time use for mothers and fathers: A case study of Spain and Sweden. Society, Health \& Vulnerability 8: 1374103. 
Hagqvist, Emma, Stig Vinberg, and Bodil Johanne Landstad. 2018. The leader identity-A means to experience conflict and constructing balance. Paper presented at 10th Biennial Gender, Work \& Organization Conference, Sydney, Australia, June 14-16.

Hilbrecht, Margo, and Donna S. Lero. 2014. Self-employment and family life: Constructing work-life balance when you're always on. Community, Work E Family 17: 20-42.

Hobson, Barbara, and Susanne Fahlén. 2009. Competing scenarios for European fathers: Applying Sen's capabilities and agency framework to work-family balance. The ANNALS of the American Academy of Political and Social Science 624: 214-33. [CrossRef]

Johansson Sevä, Ingemar, and Ida Öun. 2015. Self-Employment as a Strategy for Dealing with the Competing Demands of Work and Family? The Importance of Family/Lifestyle Motives. Gender, Work E Organization 22: 256-72.

Kirkwood, Jodyanne. 2009. Motivational factors in a push-pull theory of entrepreneurship. Gender in Management: An International Journal 24: 346-64. [CrossRef]

Kirkwood, Jodyanne, and Beth Tootell. 2008. Is entrepreneurship the answer to achieving work-family balance? Journal of Management and Organization 14: 285-302.

Korpi, Walter. 2000. Faces of inequality: Gender, class, and patterns of inequalities in different types of welfare states. Social Politics 7: 127-91. [CrossRef]

Korpi, Walter. 2010. Class and gender inequalities in different types of welfare states: The Social Citizenship Indicator Program (SCIP). International Journal of Social Welfare 19: 14-24. [CrossRef]

Korpi, Walter, Tommy Ferrarini, and Stefan Englund. 2013. Women's opportunities under different family policy constellations: Gender, class, and inequality tradeoffs in western countries re-examined. Social Politics: International Studies in Gender, State E Society 20: 1-40.

Kunda, Gideon, Stephen R. Barley, and James Evans. 2002. Why do contractors contract? The experience of highly skilled technical professionals in a contingent labor market. ILR Review 55: 234-61. [CrossRef]

Kunovich, Robert M., and Sheri Kunovich. 2008. Gender Dependence and Attitudes toward the Distribution of Household Labor: A Comparative and Multilevel Analysis. International Journal of Comparative Sociology 49: 395-427. [CrossRef]

Landstad, Bodil J., Marianne Hedlund, and Stig Vinberg. 2017. How managers of small-scale enterprises can create a health promoting corporate culture. International Journal of Workplace Health Management 10: $228-48$. [CrossRef]

Leineweber, Constanze, Maria Baltzer, Linda L. Magnusson Hanson, and Hugo Westerlund. 2013. Work-family conflict and health in Swedish working women and men: A 2-year prospective analysis (the SLOSH study). The European Journal of Public Health 23: 710-16. [CrossRef] [PubMed]

Lunau, Thorsten, Clare Bambra, Terje A. Eikemo, Kjetil A. van Der Wel, and Nico Dragano. 2014. A balancing act? Work-life balance, health and well-being in European welfare states. The European Journal of Public Health 24: 422-27. [CrossRef] [PubMed]

McGinnity, Frances, and Emma Calvert. 2009. Work-life conflict and social inequality in Western Europe. Social Indicators Research 93: 489-508. [CrossRef]

Mellner, Christin. 2016. After-hours availability expectations, work-related smartphone use during leisure, and psychological detachment: The moderating role of boundary control. International Journal of Workplace Health Management 9: 146-64. [CrossRef]

Mellner, Christin, Gunnar Aronsson, and Göran Kecklund. 2014. Boundary management preferences, boundary control, and work-life balance among full-time employed professionals in knowledge-intensive, flexible work. Nordic Journal of Working Life Studies 4: 7-23. [CrossRef]

Nordenmark, Mikael, Stig Vinberg, and Mattias Strandh. 2012. Job control and demands, work-life balance and wellbeing among self-employed men and women in Europe. Voulnerable Groups E Inclusion 3: 18896.

Nordström, Carin. 2015. The Passionate Combining Entrepreneurs. Ph.D. dissertation, Mid Sweden University, Östersund, Sweden.

OECD. 2018. Self-Employment Rate (Indicator). Available online: 10.1787/fb58715e-en (accessed on 3 August 2018).

Stephan, Ute, and Ulrike Roesler. 2010. Health of entrepreneurs versus employees in a national representative sample. Journal of Occupational and Organizational Psychology 83: 717-38. [CrossRef]

The European Institute for Gender Equality (EIGE). 2013. Gender Equality Index Report. Brussels: European Union. 
Thévenon, Olivier. 2011. Family policies in OECD countries: A comparative analysis. Population and Development Review 37: 57-87. [CrossRef] [PubMed]

Thorgren, Sara, Carin Nordström, and Joakim Wincent. 2014. Hybrid entrepreneurship: The importance of passion. Baltic Journal of Management 9: 314-29. [CrossRef]

Van der Lippe, Tanja, Annet Jager, and Yvonne Kops. 2006. Combination pressure the paid work-family balance of men and women in European countries. Acta Sociologica 49: 303-19. [CrossRef]

Wennberg, Karl, Frédéric Delmar, and Tim Folta. 2009. Dynamiken bland företagare, anställda och kombinatörer. Arbetsmarknad E Arbetsliv 15: 43-54.

West, Candace, and Don H. Zimmerman. 1987. Doing gender. Gender \& Society 1: 125-51.

World Economic Forum. 2015. Global Gender Gap Report 2015. Geneva: World Economic Forum.

(C) 2018 by the authors. Licensee MDPI, Basel, Switzerland. This article is an open access article distributed under the terms and conditions of the Creative Commons Attribution (CC BY) license (http:/ / creativecommons.org/licenses/by/4.0/). 